\title{
Migraine, obesity and body fat distribution - a population-based study
}

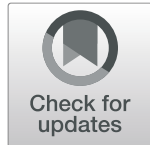

\author{
Espen Saxhaug Kristoffersen ${ }^{1,2,3^{*}}$ (D), Sigrid Børte ${ }^{1}$, Knut Hagen ${ }^{4,5}$, John-Anker Zwart ${ }^{6,7}$ and \\ Bendik Slagsvold Winsvold ${ }^{7}$
}

\begin{abstract}
Background: Obesity has been linked to an increased prevalence of migraine, and to increased migraine attack frequency, but several questions are left unanswered by previous studies. We examined the relationship between obesity and headache in a large, population-based study where we could take into account body fat distribution, migraine subtypes and tension-type headache.
\end{abstract}

Methods: The third population-based Nord-Trøndelag Health Study (HUNT3) included validated headache questionnaires and objective anthropometric measurements. Using a cross-sectional design, our sample consisted of 18,191 women and 14,985 men, aged 19 to 96 years. Of these 4290 (12.9\%) had migraine, 4447 (13.4\%) had frequent tension-type headache $(T \mathrm{TH})$, and 24,439 were headache-free controls. A total of 5049 individuals with unclassified headache were excluded from the analyses. Using logistic regression, we modeled the association between obesity and headache prevalence, adjusting for relevant confounders.

Results: Both total body obesity $(\mathrm{TBO})$ and abdominal obesity $(\mathrm{AO})$ were associated with a higher prevalence of migraine when compared to headache-free controls (OR 1.45 95\% Cl 1.32-1.59 and OR 1.29 95\% Cl 1.18-1.41, respectively), in particular for individuals < 50 years of age (OR 1.74 95\% Cl 1.54-1.98 and OR 1.89 95\% Cl 1.69-2.11). Similar results were seen for migraine with and without aura. Similar Overall, a weaker associations were as observed between obesity and $\mathrm{TH}$. There was a dose-response relationship between obesity categories and increased headache frequency in subjects with migraine. TBO was associated with migraine prevalence and attack frequency independent of $\mathrm{AO}$.

Conclusion: Both TBO and $\mathrm{AO}$ were associated with migraine prevalence and attack frequency. This association was largely limited to individuals $<50$ years of age. TBO, rather than $\mathrm{AO}$, may be a better measure of obesity in relation to migraine.

Keywords: Body mass index, Obese, Pain, General population

\section{Background}

The prevalence of overweight and obesity has increased substantially in the last decades, and is now one of the leading risk factors for disease and death worldwide [1,

\footnotetext{
* Correspondence: e.s.kristoffersen@medisin.uio.no

${ }^{1}$ Research and Communication Unit for Musculoskeletal Health, Division of Clinical Neuroscience, Oslo University Hospital, Oslo, Norway

${ }^{2}$ Department of General Practice, HELSAM, University of Oslo, PO Box 1130, Blindern, 0318 Oslo, Norway

Full list of author information is available at the end of the article
}

2]. Total body obesity (TBO), as measured by body mass index (BMI), has been associated with migraine prevalence, and with the progression from episodic to chronic migraine [3-10]. Several questions are, however, left unanswered by previous studies. First, obesity defined from BMI cannot distinguish between fat and muscle mass or between abdominal and peripheral fat distribution [11, 12]. Abdominal visceral fat is metabolically different from other body fat, and appears to be an independent

(c) The Author(s). 2020 Open Access This article is licensed under a Creative Commons Attribution 4.0 International License, which permits use, sharing, adaptation, distribution and reproduction in any medium or format, as long as you give appropriate credit to the original author(s) and the source, provide a link to the Creative Commons licence, and indicate if changes were made. The images or other third party material in this article are included in the article's Creative Commons licence, unless indicated otherwise in a credit line to the material. If material is not included in the article's Creative Commons licence and your intended use is not permitted by statutory regulation or exceeds the permitted use, you will need to obtain permission directly from the copyright holder. To view a copy of this licence, visit http://creativecommons.org/licenses/by/4.0/ The Creative Commons Public Domain Dedication waiver (http://creativecommons.org/publicdomain/zero/1.0/) applies to the data made available in this article, unless otherwise stated in a credit line to the data. 
risk factor for medical complications [12, 13]. Abdominal obesity (AO) may be of particularly interest in migraine, as this adipose tissue produces multiple substances potentially involved in migraine pathophysiology, including markers of systemic inflammation [14]. Waist circumference has been suggested as a better measure of abdominal fat than BMI, and may be better suited to predict future health risks $[11,12,15,16]$. However, most previous population-studies of obesity and migraine have been based on BMI rather than $\mathrm{AO}$ $[11-13,15]$. Second, both fat distribution and migraine prevalence vary substantially with sex and age, and it is possible that the relationship between the two also changes with these factors $[5,8,10,17]$. Interestingly, population-based studies of older individuals typically find no association between obesity and migraine, while studies of reproductive-age individuals find substantial associations $[7,8]$. Third, tension-type headache (TTH) has typically not been examined by these populationbased studies.

Our aim was to determine how obesity and body fat distribution $\mathrm{TBO}$ and $\mathrm{AO}$ were associated with migraine and TTH in a large population-based study. That included validated headache diagnoses and objective anthropomorphic measurements.

Secondly, we explored how this association changed with age and sex, and whether there was a doseresponse relationship between obesity measures and headache frequency.

\section{Methods}

\section{Study sample}

All inhabitants 20 years or older in Nord-Trøndelag county of Norway were invited to participate in the third Nord-Trøndelag Health Study (HUNT3) (2006-2008). The study population, including both participants and non-participants has been described in detail previously [18]. In brief, two questionnaires including more than 200 health-related questions were given to the participants. Of the 94,194 individuals invited, 50,807 (54\%) answered the first questionnaire (Q1) which was enclosed with the invitation letter. They were also invited to participate in a brief medical examination, including anthropometric measurements, and to fill in a second questionnaire $(\mathrm{Q} 2)$, which included a total of 14 headache questions. In total, 38,225 (41\%) participants answered Q2, had complete information on age, sex, smoking, depression measured by Hospital Anxiety and Depression Scale (HADS-D) and valid information regarding diabetes, and could be classified according to headache status. Of these 33,176 participants had either migraine, TTH or no headache, according to the classification described below, and were eligible for inclusion in the study, while 5049 participants with non-classifiable headache were excluded. There was complete information on BMI and waist circumference for 33,067 (99.7\%) and 33,027 (99.6\%).

\section{Headache classification}

The 14 headache questions in the second questionnaire (Q2) were designed mainly to determine whether the individual had headache, the frequency of headache, and, when headache were reported, to diagnose migraine and TTH according to slight modified the second version of the International Classification of Headache Disorders (ICHD-II) $[18,19]$. Subjects who answered "yes" to the screening question "Have you suffered from headache during the last 12 months?" were classified as headache sufferers. Those who answered "no" comprise the headache-free control group. Based on the subsequent headache questions, headache sufferers were classified as having migraine if they fulfilled the following three criteria: (1) headache attacks lasting $\leq 72 \mathrm{~h},(<4 \mathrm{~h}$ was accepted because participants were not asked for duration of untreated attacks in the question "How long does the headache usually last?); (2) headache had usually at least two of the following characteristics: pulsating quality, unilateral location, moderate/severe pain intensity or aggravation by physical activity; (3) during headache, at least one of the following: nausea/vomiting, photophobia and phonophobia. Migraine with aura was defined as migraine and typical visual disturbance prior or during headache. Headache sufferers were classified as having TTH if they fulfilled the following criteria: (i) Headache at least one day a month. (ii) Headache with at least two of the following characteristics: bilateral location, pressing quality, mild to moderate intensity and no aggravation by physical activity. (iii) During headache no nausea or vomiting and no phonophobia or photophobia. The headache diagnoses were mutually exclusive, with migraine taking precedence over TTH. Migraine or TTH was classified as episodic if the participant reported headache on $\leq 14$ days per month, and chronic if $>14$ days per month. The headache diagnoses have previously been validated against clinical interviews by neurologists [18]. The sensitivity and specificity were, respectively, $88 \%$ and $86 \%$ for any headache (Cohen's kappa $(\kappa)=0.70,95 \%$ CI $0.61-0.79), 51 \%$ and $95 \%$ for migraine $(\kappa=0.50,95 \%$ CI $0.32-0.68), 50 \%$ and $95 \%$ for migraine with aura $(\kappa=0.44,95 \%$ CI $0.38-0.50)$, and $96 \%$ and $69 \%$ for TTH $(\kappa=0.44,95 \%$ CI $0.30-0.58)$.

\section{Anthropometric measurements}

Height and weight were measured with standardized weight scales and metric bands. The participants wore light clothes and no shoes. Height was measured to the nearest $1.0 \mathrm{~cm}$, and weight to the nearest $0.5 \mathrm{~kg}$. BMI was defined as weight/height 2 and computed in $\mathrm{kg} / \mathrm{m} 2$. 
BMI status in adults were categorized into four TBO levels; underweight $(\mathrm{BMI}<18.5)$, normal weight $(18.5 \leq$ $\mathrm{BMI}<25)$, overweight $(25 \leq \mathrm{BMI}<30)$ and obese $(\mathrm{BMI} \geq$ 30) in accordance to World Health Organization (WHO) definitions [11].

Waist circumference (WC) was measured to the nearest $\mathrm{cm}$ applying non-stretchable band horizontally at the umbilical level after the participants emptied their lungs, or midway between the last rib and the iliac cristae if the latter was larger. $\mathrm{AO}$ was defined from $\mathrm{WC}$ and categorized into three levels according to WHO criteria [11]; normal weight (women $<80 \mathrm{~cm}$, men $<94 \mathrm{~cm}$ ), abdominal overweight (women $80-88 \mathrm{~cm}$, men $94-102 \mathrm{~cm}$ ) and abdominal obesity (women $>88 \mathrm{~cm}$, men $>102$ ).

\section{Potential confounders}

In accordance with a pre-planned strategy, it was decided to include the following variables available from HUNT3 as potential confounders because of their known impact on headache and obesity: sex (binary); age at participation (continuous); any history of diabetes (binary); current daily tobacco smoking (binary); and HADS-D (continuous). While HUNT3 included a wide range of health-related information, including several factors that have previously been associated with either headache or migraine [20], we limited the list to these potential confounders to avoid over-adjustment bias [21].

\section{Statistical analysis}

The association between headache and obesity was tested using logistic regression models. We estimated odds ratios (OR) and 95\% confidence intervals (CI) for the association between anthropometric measures (exposure) and headache (outcome), using headache-free participants as controls. The exposure was either TBO categories (4 levels) or abdominal obesity (3 levels) as described above. Separate analyses were performed for migraine and TTH. Based on previous knowledge that body fat distribution and headache prevalence differ strongly by sex and age, we next performed analyses stratified by sex and by age $<50$ years or $\geq 50$ years of age. The cut-off of 50 years was based on the prior knowledge of headache prevalence and the hormonal changes in women during the menopause [22]. Lastly, to estimate whether the effects of TBO and abdominal obesity were independent of each other, we modelled the effect of each, adjusting for the other. To limit the number of tests, this additional adjustment was included only in the main (non-stratified) analyses and in analyses of headache frequency. Two-tailed $P$-values are reported, using $5 \%$ as a cut-off for statistical significance. Data analysis was performed with the IBM Statistical Package for the Social Sciences, version 26 (SPSS, Chicago, Illinois, USA).

\section{Results}

Our final sample consisted of 33,176 individuals, with a mean age of 54.4 years (range 19 to 96 years). Of these, $4290(12.9 \%)$ had migraine and 4447 (13.4\%) had TTH. Details are given in Table 1.

\section{Total body obesity}

In adjusted analyses (Tables 2 and 3), TBO (BMI $\geq 30$ ) was associated with increased odds for having migraine (OR 1.45, 95\% CI 1.32-1.59), both for women and for men. The effect size was larger when considering only participants < 50 years of age (OR 1.74, 95\% CI 1.541.98 ), and not seen for those $\geq 50$ years. A more moderate association was observed in women between migraine and being overweight (BMI 25-30) (OR 1.23, 95\% CI 1.11-1.35), not statistically significant in men (Table 3). In analyses of migraine subtypes, obesity was associated with higher odds for having both migraine with aura (OR 1.51, 95\% CI 1.33-1.71) and migraine without aura (OR 1.43 95\% CI 1.26-1.62). Likewise, being overweight (BMI 25-30) was associated with higher odds for having migraine with aura (OR 1.25 95\% CI 1.12-1.39) and migraine without aura (OR 1.15 95\% CI 1.04-1.29). Similar, but weaker associations were seen for TTH (Tables 2 and 3). In supplementary analyses, When including additionally adjustmented for degree of abdominal obesity ( 3 levels), the association between migraine and obesity (OR 1.44, 95\% CI 1.26-1.63) and migraine and overweight (OR 1.19 95\% CI 1.08-1.31) remained, while the association between TTH and obesity (1.13 95\% CI 1.00-1.28) and TTH and overweight (1.05 95\% CI 0.96-1.15), were less clear (data not shown). weaker.

\section{Abdominal obesity (AO)}

Results for $\mathrm{AO}$ in adjusted analyses (Tables 2 and 3) were similar to those for $\mathrm{BMI}$. $\mathrm{AB}$ (WC $>88 \mathrm{~cm}$ in women, $>102 \mathrm{~cm}$ in men) was associated with increased odds for having migraine (OR 1.29, 95\% CI 1.18-1.41), seen both for women and for men. The effect size was larger when considering only participants $<50$ years (OR $1.89,95 \%$ CI 1.69-2.11), but there was also an association for participants $\geq 50$ years of age (OR $1.26,95 \%$ CI 1.10-1.45). A more moderate association was observed between migraine and being abdominal overweight (WC 80-88 in women, 94-102 in men), not statistically significant in women. In analyses of migraine subtypes, abdominal obesity was associated with higher odds for having both migraine with aura (OR 1.39 95\% CI 1.231.57) and migraine without aura (OR 1.21 95\% CI 1.071.36). Likewise, being abdominal overweight was 
Table 1 Clinical profile of participants

\begin{tabular}{llll}
\hline & No headache $n=24,439$ & Migraine $n=4290$ & Tension-type headache $n=4447$ \\
\hline $\begin{array}{l}\text { Discrete variables, } n \text { (\%) } \\
\text { Female }\end{array}$ & $12,280(50.2)$ & $3158(73.6)$ & $2753(61.9)$ \\
Daily smoking & $4237(17.3)$ & $933(21.7)$ & $844(19.0)$ \\
Diabetes & $1262(5.2)$ & $105(2.4)$ & $147(3.3)$ \\
Continuous variables, mean (SD) & & & $49.3(14.0)$ \\
Age (years) & $56.7(15.6)$ & $46.2(12.9)$ & $3.9(2.9)$ \\
HADS depression score & $3.2(2.8)$ & $3.6(3.2)$ & $27.3(4.6)$ \\
Body-mass index & $27.2(4.2)$ & $27.3(5.0)$ & $93.2(12.8)$ \\
Waist circumference & $94.1(11.9)$ & $92.1(13.2)$ & \\
\hline
\end{tabular}

$S D$ standard deviation, HADS Hospital Anxiety and Depression Scale

associated with higher odds for having migraine with aura (OR 1.15 95\% CI 1.01-1.31) and migraine without aura (OR 1.16 95\% CI 1.02-1.31). Associations between TTH and abdominal overweight and obesity were similar to those seen for migraine (Tables 2 and 3). In supplementary analyses, including adjustment When additionally adjusted for degree of TBO (4 levels), there was no association between migraine and AO (OR 1.02, 95\% CI 0.90-1.16) or between migraine and abdominal overweight (OR 1.06 95\% CI 0.96-1.17), while for TTH there was still an association with AO (OR 1.16 95\% CI 1.031.30) and abdominal overweight (OR 1.15 95\% CI 1.051.27) (data not shown).

\section{Obesity and headache frequency}

TBO (BMI $\geq 30)$ and $\mathrm{AO}$ (WC $>88 \mathrm{~cm}$ in women, $>102$ $\mathrm{cm}$ in men) were associated with both episodic and chronic migraine, with higher effect sizes for chronic than for episodic migraine (Table 4). TBO and AO were associated with episodic, but not with chronic, TTH.
For subjects with migraine, the association between headache frequency and TBO remained after additionally adjusting the model for AO (2 levels; obese or nonobese) (OR 1.19 95\% CI 1.08-1.32 for episodic headache; OR 1.43, 95\% CI 1.02-2.00 for chronic headache). In contrast, after adjusting for TBO (2 levels; obese or nonobese), there was no remaining association between headache frequency and AO (OR 1.04 95\% CI 0.95-1.14 for episodic headache; OR 1.10 95\% CI 0.80-1.51 for chronic headache). In corresponding adjusted analyses for TTH, only a weak association remained between episodic TTH and AO, after adjusting for TBO (OR 1.10 95\% CI 1.01-1.20).

\section{Discussion}

In this large population-based study both TBO and AO were associated with a higher prevalence of migraine. The associations were mostly limited to individuals $<50$ years of age. There was a dose-response relationship between obesity categories and increased headache

Table 2 Association between obesity and headache

\begin{tabular}{|c|c|c|c|}
\hline & No headache $N$ & Migraine OR $(95 \% \mathrm{Cl}) \mathrm{N}$ & Tension-type headache OR $(95 \% \mathrm{CI}) \mathrm{N}$ \\
\hline \multicolumn{4}{|l|}{ Obesity (BMI) $^{a}$} \\
\hline Underweight & 121 & $1.17(0.78-1.74) 38$ & $0.83(0.53-1.31) 24$ \\
\hline Normal weight & 7519 & 1.0 (Ref.) 1455 & 1.0 (Ref.) 1469 \\
\hline Overweight & 11,289 & $1.19 * * *(1.10-1.29) 1710$ & $1.11^{* *}(1.03-1.20) 1893$ \\
\hline Obese & 5424 & $1.45^{* * *}(1.32-1.59) 1071$ & $1.26^{* * *}(1.15-1.38) 1054$ \\
\hline \multicolumn{4}{|l|}{ Abdominal obesity $(\mathrm{WC})^{\mathrm{b}}$} \\
\hline Normal weight & 6633 & 1.0 (Ref.) 1090 & 1.0 (Ref.) 1141 \\
\hline Abdominal overweight & 7638 & $1.16^{* *}(1.05-1.27) 1232$ & $1.20^{* * *}(1.09-1.31) 1367$ \\
\hline Abdominal obesity & 10,066 & $1.29 * * *(1.18-1.41) 1935$ & $1.27^{* * *}(1.17-1.39) 1925$ \\
\hline
\end{tabular}

${ }^{* *} p<0.01$; ${ }^{* * *} p<0.001$

a Underweight $(\mathrm{BMI}<18.5)$, normal weight $(18.5 \leq \mathrm{BMl}<25)$, overweight $(25 \leq \mathrm{BMI}<30)$, obese $(\mathrm{BMI} \geq 30)$

${ }^{b}$ Normal weight (WC for women $<80 \mathrm{~cm}$, for men $<94 \mathrm{~cm}$ ), abdominal overweight (women $80-88 \mathrm{~cm}$, men $94-102 \mathrm{~cm}$ ), abdominal obesity (women $>88 \mathrm{~cm}$, men > 102)

$O R$ odds ratio, $\mathrm{Cl}$ confidence intervals, Ref. reference category, $B M I$ body mass index, WC waist circumference

The analyses are adjusted for age, sex, smoking, depression (HADS-D) and presence of diabetes 


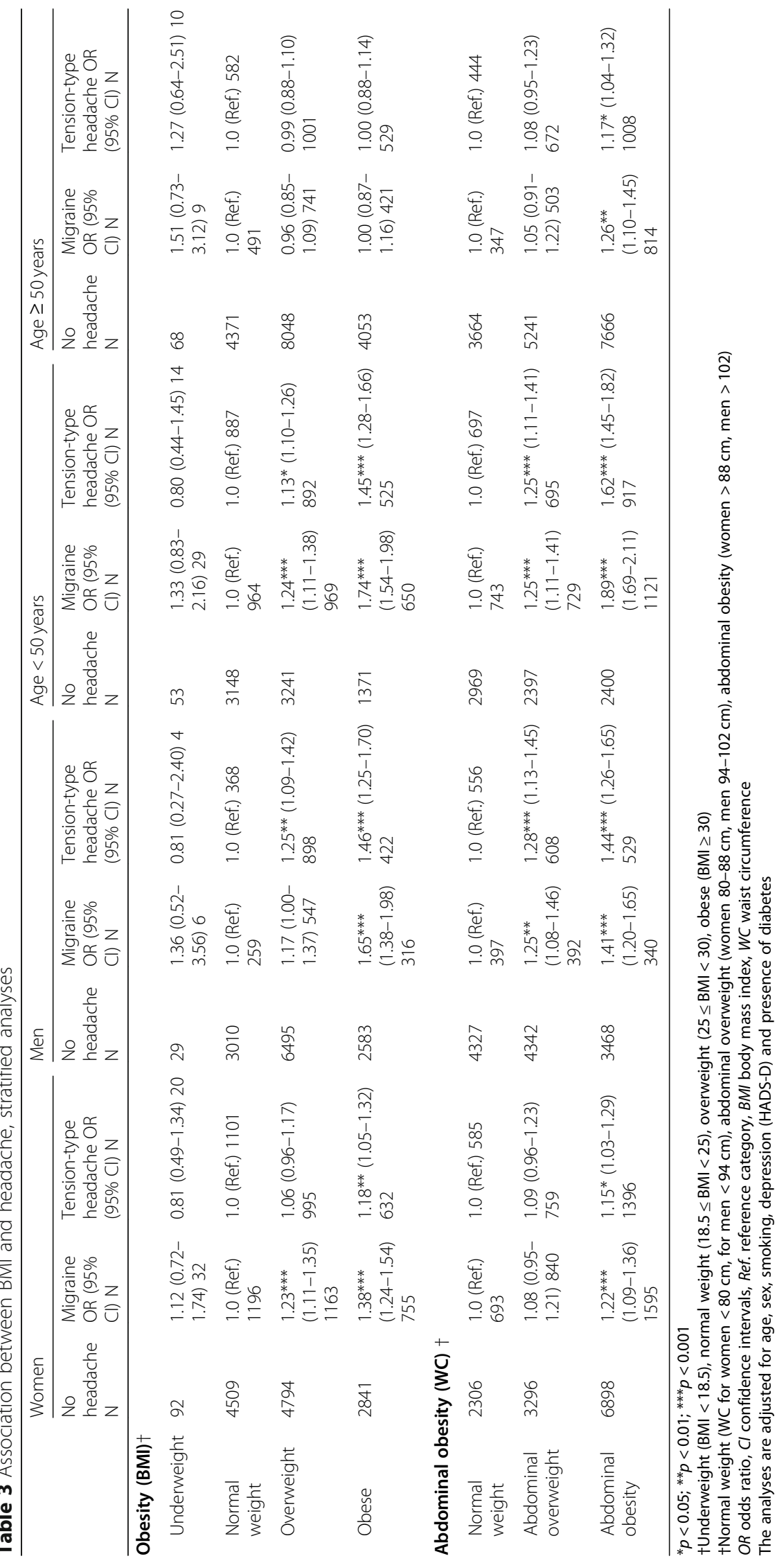


Table 4 Obesity by headache frequency

\begin{tabular}{llllll}
\hline & & Non-obese (BMI) A & Obesity (BMI) B & Non-obese (WC) C Abdominal obesity (WC)D \\
\hline Headache status & Headache frequency & $\mathrm{N}$ & $\mathrm{OR}(95 \% \mathrm{Cl}) \mathrm{N}$ & $\mathrm{N}$ & $\mathrm{OR}(95 \% \mathrm{Cl})$ \\
No headache & & 18,929 & 1.0 (Ref.) 5424 & 14,271 & 1.0 (Ref.) 10,066 \\
Tension-type headache & Episodic ( $\leq 14$ days/month) & 3141 & $1.15^{* *}(1.06-1.25) 964$ & 2320 & $1.15^{* * *}(1.07-1.24) 1778$ \\
& Chronic (> 14 days/month) & 245 & $1.27(0.99-1.62) 90$ & 188 & $1.03(0.82-1.30) 147$ \\
Migraine & Episodic ( $\leq 14$ days/month) & 3015 & $1.25^{* * *}(1.16-1.36) 995$ & 2191 & $1.15^{* * *}(1.07-1.24) 1805$ \\
& Chronic (> 14 days/month) & 174 & $1.53^{* *}(1.16-2.02) 74$ & 120 & $1.36^{*}(1.04-1.76)$ S125 \\
\hline
\end{tabular}

$O R$ odds ratio, $\mathrm{Cl}$ confidence intervals, Ref. reference category, $\mathrm{BMI}$ body mass index

ABody-mass index $<30$. BBody-mass index $\geq 30$. CWaist circumference $\leq 88 \mathrm{~cm}$ for women, $\leq 102 \mathrm{~cm}$ for men. DWaist circumference $>88 \mathrm{~cm}$ for women, $>102 \mathrm{~cm}$ for men. ${ }^{*} p<0.05 ;{ }^{* *} p<0.01 ;{ }^{* * *} p<0.001$. Analyses are adjusted for age, sex, smoking, depression (HADS-D) and presence of diabetes

frequency in subjects with migraine. Regarding body fat distribution, the association between migraine and TBO was independent of $\mathrm{AO}$, but not vice versa, suggesting that TBO may be a more important measure with regards to migraine prevalence and chronification. Similar, but weaker associations, were seen for TTH.

The relationship between headaches and obesity was suggested in a prospective population-based 11-months follow-up study from US in 2003 [6]. Study subjects with increased BMI ( $>25$ ) had an increased relative risk of developing chronic headache (>14 days/months), compared to normal-weight individuals. This study did not differentiate between headache types, but other cross-sectional population-based studies found an association between obesity and increased migraine frequency, giving credibility to the notion that obesity is a driving factor for migraine progression $[3,4,9,23]$. In line with previous studies, we found a dose-response relationship between obesity and migraine frequency. Our results also indicate that the association is driven by TBO rather than by $\mathrm{AO}$.

Obesity has also been associated with an increased prevalence of migraine. Two recent meta-analyses found that obese individuals had an overall increased risk of migraine of $14 \%$ versus $27 \%$ when compared with those with normal weight $[7,8]$. However, most of the studies reviewed were based on BMI from self-reported height and weight. Also, the authors commented that further studies of the association between migraine and obesity should take into account age, gender, headache type and headache frequency, to provide more robust evidence. Ageing is associated with a change in the ratio of fat and lean body mass even in those with an unchanged BMI. In addition, the overall adipose tissue distribution is different in women and men, with younger women having more adipose tissue in a gluteofemoral distribution than abdominally, while men of all ages and older women have more abdominal adipose tissue depots then young women. One, previous population-based study examined the prevalence of migraine by $\mathrm{TBO}$ and $\mathrm{AO}$, and found that the association between migraine and obesity varied by age, sex, and adipose tissue distribution [5]. In men and women aged 55 years or younger, migraine prevalence was increased in those with $\mathrm{TBO}(\mathrm{BMI} \geq 30)$, independent of $\mathrm{AO}$. In men older than 55 years, migraine was not associated with obesity. However, in women older than 55 years, migraine prevalence was decreased among those with AO. This study could not classify TTH or migraine with and without aura, and did not include measures of headache frequency [5]. Our results confirm this and previous reports of a positive association between migraine and both $\mathrm{TBO}$ and $\mathrm{AO}$. We extend the results in showing a similar association for migraine with aura, migraine without aura, and TTH. We also confirm that the association between obesity and headache is mostly restricted to younger individuals.

Based on findings in pre-clinical and clinical studies various mechanisms have been suggested to explain the association between migraine and obesity, including metabolic and hormonal activity of adipose tissue, increased release of pro-inflammatory substances, neuroinflammation and neuropeptides involving hypothalamic function [7, 8, 17, 24, 25]. Adiponectin and leptin are adipokines that are mostly released from subcutaneous adipose tissue, and that may have nociceptive traits in themselves [17, 26-28]. Both adiponectin and leptin are increased in migraineurs between attacks, although they may be decreased during attacks [17, 29]. Leptin levels are also increased in correlation with proinflammatory cytokines IL-6 and TNF-a [29], which have also been found to be elevated in people with migraine [30]. Serotonin and orexin A are neuropeptides that function as appetite regulators and are linked to obesity. They are also possibly linked to migraine pathophysiology, however this is still debated, along with the involvement and dysregulation of hypothalamic and homeostatic pathways [31-33].

A causal relationship between migraine and obesity can have important implications for clinicians, patients and future public health strategies, also in light of the increased risk of cardiovascular diseases in both migraine and obesity [2, 16, 34, 35]. Studies that have investigated the effect of weight loss on migraine have mostly examined dietary interventions, but gastric bypass has also 
been evaluated [24]. A recent systematic review concludes that weight reduction improves the frequency and duration of attacks in patients who have migraine and obesity, independently of the type of intervention and the amount of weight reduction [36]. Follow-up studies are needed to confirm this, and to provide a better understanding on the mechanisms linking migraine and obesity.

Strengths of our study include the large and unselected population, and the use of validated headache diagnoses and standardized anthropometric measurements. The general health focus of the questionnaires decreases the risk of a specific selection bias in relation to headache diagnoses. In the multivariate analyses we could adjust for several relevant potential confounders. However, the possibility of residual confounding cannot be excluded in this observational study. The migraine diagnoses were validated and based on the ICHD-criteria [18]. Although HUNT3 used the ICHD-II criteria, the migraine criteria did not change to the present ICHD-3 $[19,37]$. A limitation of the study was the use of questionnaire-based headache diagnoses rather than clinical interview. This will lead to a degree of misclassification between migraine and other types of headache. Furthermore, it should be highlighted that mutually exclusive headache diagnosis was set only in individuals answering "yes" to the screening question "Have you suffered from headache during the last 12 months?" This is the main reason of the very low prevalence of THH of $13.4 \%$ in the present study. Thus, individuals without headache also included those with infrequent TTH (or migraine) without defining themselves as being headache sufferers. Another limitation of the study is that our question-based headache diagnosis did not identify secondary headaches associated with obesity, e.g. idiopathic intracranial hypertension or obstructive sleep apnea [38, 39]. On the other hand, such secondary headaches are relatively rare in the general population $[39,40]$. However, the agreement between questionnaire-based diagnosis of migraine and interview has previously been found to be acceptable [18]. Finally, it should also be highlighted that the crosssectional design does not permit any conclusions about causality, and that the results should be generalized with caution based on the $42 \%$ responder rate to the HUNT3 headache questionnaire.

\section{Conclusion}

In this large population-based study both total body obesity and abdominal obesity were associated with a higher prevalence of migraine. There was a doseresponse relationship between increased obesity and increased headache frequency in subjects with migraine. These findings may have clinical implications for treatment of migraine and should be further investigated in population-based follow-up studies.

\section{Abbreviations}

HADS: Hospital Anxiety and Depression Scale; HUNT: The Nord-Trøndelag Health Study; ICHD: International Classification of Headache Disorders; Cl: Confidence interval; BMI: Body Mass Index; WC: Waist Circumference; TBO: Total body obesity; AO: Abdominal obesity; OR: Odds Ratio;

TTH: Tension-type headache

\section{Acknowledgments}

The Nord-Trøndelag Health Study (The HUNT Study) is a collaboration between HUNT Research Centre (Faculty of Medicine, Norwegian University of Science and Technology NTNU), Nord-Trøndelag County Council, Central Norway Health Authority, and the Norwegian Institute of Public Health.

\section{Authors' contributions}

ESK and BWS had the original idea for the study and together with SB and JAZ planned the overall design. ESK prepared the initial draft and was the main author of the present manuscript. ESK and BWS conducted the data analyses. All authors planned the statistics methodology and were involved in all analyses. All authors have read, revised and approved the final manuscript.

\section{Funding}

This study is supported by grants from the University of Oslo, Akershus University Hospital and Oslo University Hospital. The funding sources had no role in the design of the study; the collection, analysis, and interpretation of the data, preparation of the manuscript; or the decision to submit the manuscript for publication.

\section{Availability of data and materials}

The authors declare that the data supporting the findings of this study are available within the article.

\section{Ethics approval and consent to participate}

The study was approved by the Regional Committee for Ethics in Medical Research (2014/644/REK sør-øst), and the HUNT Study was in addition approved by the Norwegian Data Inspectorate.

\section{Consent for publication}

Not applicable.

\section{Competing interests}

The authors declare that they have no conflicts of interest

\section{Author details}

${ }^{1}$ Research and Communication Unit for Musculoskeletal Health, Division of Clinical Neuroscience, Oslo University Hospital, Oslo, Norway. ${ }^{2}$ Department of General Practice, HELSAM, University of Oslo, PO Box 1130, Blindern, 0318 Oslo, Norway. ${ }^{3}$ Department of Neurology, Akershus University Hospital, Lørenskog, Norway. ${ }^{4}$ Department of Neuromedicine and Movement science, Norwegian University of Science and Technology, Trondheim, Norway.

${ }^{5}$ Clinical Research Unit Central Norway, St. Olavs University Hospital,

Trondheim, Norway. ${ }^{6}$ Institute of Clinical Medicine, University of Oslo, Oslo, Norway. ${ }^{7}$ Department of Research, Innovation and Education, Division of

Clinical Neuroscience, Oslo University Hospital, Oslo, Norway.

Received: 17 June 2020 Accepted: 21 July 2020

Published online: 06 August 2020

\section{References}

1. NCD Risk Factor Collaboration (NCD-RisC) (2017) Worldwide trends in bodymass index, underweight, overweight, and obesity from 1975 to 2016: a pooled analysis of 2416 population-based measurement studies in 128.9 million children, adolescents, and adults. Lancet 390(10113):2627-42.

2. Afshin A, Forouzanfar MH, Reitsma MB, Sur P, Estep K, Lee A et al (2017) Health effects of overweight and obesity in 195 countries over 25 years. N Engl J Med 377(1):13-27

3. Bigal ME, Liberman JN, Lipton RB (2006) Obesity and migraine: a population study. Neurology. 66(4):545-550

4. Bigal ME, Tsang A, Loder E, Serrano D, Reed ML, Lipton RB (2007) Body mass index and episodic headaches: a population-based study. Arch Intern Med 167(18):1964-1970 
5. Peterlin BL, Rosso AL, Rapoport AM, Scher Al (2010) Obesity and migraine: the effect of age, gender and adipose tissue distribution. Headache. 50(1): 52-62

6. Scher Al, Stewart WF, Ricci JA, Lipton RB (2003) Factors associated with the onset and remission of chronic daily headache in a population-based study. Pain. 106(1-2):81-89

7. Gelaye B, Sacco S, Brown WJ, Nitchie HL, Ornello R, Peterlin BL (2017) Body composition status and the risk of migraine: a meta-analysis. Neurology. 88(19):1795-1804

8. Ornello R, Ripa P, Pistoia F, Degan D, Tiseo C, Carolei A et al (2015) Migraine and body mass index categories: a systematic review and meta-analysis of observational studies. J Headache Pain. 16:27

9. Winter AC, Berger K, Buring JE, Kurth T (2009) Body mass index, migraine, migraine frequency and migraine features in women. Cephalalgia. 29(2): 269-278

10. Peterlin $B L$, Rosso AL, Williams MA, Rosenberg JR, Haythornthwaite JA, Merikangas KR et al (2013) Episodic migraine and obesity and the influence of age, race, and sex. Neurology. 81(15):1314-1321

11. World Health Organization (2011) Waist circumference and waist-hip ratio report of a WHO expert consultation, Geneva, 8-11 December 2008. World Health Organization, Geneva

12. Ross R, Neeland IJ, Yamashita S, Shai I, Seidell J, Magni P et al (2020) Waist circumference as a vital sign in clinical practice: a consensus statement from the IAS and ICCR working group on visceral obesity. Nat Rev Endocrinol 16(3):177-189

13. Janssen I, Katzmarzyk PT, Ross R (2004) Waist circumference and not body mass index explains obesity-related health risk. Am J Clin Nutr 79(3):379-384

14. Panagiotakos DB, Pitsavos C, Yannakoulia M, Chrysohoou C, Stefanadis C (2005) The implication of obesity and central fat on markers of chronic inflammation: the ATTICA study. Atherosclerosis. 183(2):308-315

15. Rankinen T, Kim SY, Perusse L, Despres JP, Bouchard C (1999) The prediction of abdominal visceral fat level from body composition and anthropometry: ROC analysis. Int J Obes Relat Metab Disord 23(8):801-809

16. Cerhan JR, Moore SC, Jacobs EJ, Kitahara CM, Rosenberg PS, Adami $\mathrm{HO}$ et al (2014) A pooled analysis of waist circumference and mortality in 650,000 adults. Mayo Clin Proc 89(3):335-345

17. Peterlin BL, Sacco S, Bernecker C, Scher Al (2016) Adipokines and migraine: a systematic review. Headache. 56(4):622-644

18. Hagen K, Zwart JA, Aamodt AH, Nilsen KB, Brathen G, Helde G et al (2010) The validity of questionnaire-based diagnoses: the third Nord-Trondelag health study 2006-2008. J Headache Pain 11(1):67-73

19. Headache Classification Committee of the International Headache Society (2004) The International Classification of Headache Disorders: 2nd edition. Cephalalgia 24 Suppl 1:9-160

20. Hagen K, Stovner LJ, Zwart JA (2007) Potentials and pitfalls in analytical headache epidemiological studies--lessons to be learned from the headHUNT study. Cephalalgia. 27(5):403-413

21. Schisterman EF, Cole SR, Platt RW (2009) Overadjustment bias and unnecessary adjustment in epidemiologic studies. Epidemiology. 20(4):488-495

22. Vetvik KG, MacGregor EA (2017) Sex differences in the epidemiology, clinical features, and pathophysiology of migraine. Lancet Neurol 16(1):76-87

23. Santos IS, Goulart AC, Passos VM, Molina Mdel C, Lotufo PA, Bensenor IM (2015) Obesity, abdominal obesity and migraine: a cross-sectional analysis of ELSA-Brasil baseline data. Cephalalgia. 35(5):426-436

24. Razeghi Jahromi S, Ghorbani Z, Martelletti P, Lampl C, Togha M (2019) Association of diet and headache. J Headache Pain. 20(1):106

25. Mínguez-Olaondo A, Martínez-Valbuena I, Romero S, Frühbeck G, Luquin MR, Martínez-Vila E et al (2020) Excess abdominal fat is associated with cutaneous allodynia in individuals with migraine: a prospective cohort study. J Headache Pain 21(1):9

26. Kutlu S, Canpolat S, Sandal S, Ozcan M, Sarsilmaz M, Kelestimur H (2003) Effects of central and peripheral administration of leptin on pain threshold in rats and mice. Neuro Endocrinol Lett 24(3-4):193-196

27. Van Harmelen V, Reynisdottir S, Eriksson P, Thörne A, Hoffstedt J, Lönnqvist F et al (1998) Leptin secretion from subcutaneous and visceral adipose tissue in women. Diabetes. 47(6):913-917

28. Frederiksen L, Nielsen TL, Wraae K, Hagen C, Frystyk J, Flyvbjerg A et a (2009) Subcutaneous rather than visceral adipose tissue is associated with adiponectin levels and insulin resistance in young men. J Clin Endocrinol Metab 94(10):4010-4015
29. Dominguez C, Vieites-Prado A, Perez-Mato M, Sobrino T, Rodriguez-Osorio X, Lopez A et al (2018) Role of adipocytokines in the pathophysiology of migraine: a cross-sectional study. Cephalalgia. 38(5):904-911

30. Edvinsson L, Haanes KA, Warfvinge K (2019) Does inflammation have a role in migraine? Nat Rev Neurol 15(8):483-490

31. Deen M, Christensen CE, Hougaard A, Hansen HD, Knudsen GM, Ashina M (2017) Serotonergic mechanisms in the migraine brain - a systematic review. Cephalalgia. 37(3):251-264

32. May A, Burstein R (2019) Hypothalamic regulation of headache and migraine. Cephalalgia. 39(13):1710-1719

33. Strother LC, Srikiatkhachorn A, Supronsinchai W (2018) Targeted Orexin and hypothalamic neuropeptides for migraine. Neurotherapeutics. 15(2):377-390

34. Oie LR, Kurth T, Gulati S, Dodick DW (2020) Migraine and risk of stroke. Neurol Neurosurg Psychiatry 91(6):593-604

35. Sacco S, Ornello R, Ripa P, Tiseo C, Degan D, Pistoia F et al (2015) Migraine and risk of ischaemic heart disease: a systematic review and meta-analysis of observational studies. Eur J Neurol 22(6):1001-1011

36. Di Vincenzo A, Beghetto M, Vettor R, Tana C, Rossato M, Bond DS et al (2020) Effects of surgical and non-surgical weight loss on migraine headache: a systematic review and meta-analysis. Obes Surg 30(6):21732185

37. Headache Classification Committee of the International Headache Society (2018) The international classification of headache disorders, 3rd edition. Cephalalgia. 38(1):1-211

38. Suzuki K, Miyamoto M, Miyamoto T, Numao A, Suzuki S, Sakuta H et al (2015) Sleep apnoea headache in obstructive sleep apnoea syndrome patients presenting with morning headache: comparison of the ICHD-2 and CHD-3 beta criteria. J Headache Pain 16:56

39. Kilgore KP, Lee MS, Leavitt JA, Mokri B, Hodge DO, Frank RD et al (2017) Reevaluating the incidence of idiopathic intracranial hypertension in an era of increasing obesity. Ophthalmology 124(5):697-700

40. Russell MB, Kristiansen HA, Kværner KJ (2014) Headache in sleep apnea syndrome: epidemiology and pathophysiology. Cephalalgia. 34(10):752-755

\section{Publisher's Note}

Springer Nature remains neutral with regard to jurisdictional claims in published maps and institutional affiliations.
Ready to submit your research? Choose BMC and benefit from:

- fast, convenient online submission

- thorough peer review by experienced researchers in your field

- rapid publication on acceptance

- support for research data, including large and complex data types

- gold Open Access which fosters wider collaboration and increased citations

- maximum visibility for your research: over $100 \mathrm{M}$ website views per year

At $\mathrm{BMC}$, research is always in progress.

Learn more biomedcentral.com/submissions 